\title{
ICT ADOPTION IN SMEs: DETERMINANTS, LEVELS, AND INFLUENCE ON THE ORGANIZATIONAL INNOVATIVENESS
}

\author{
Büşra Alma Çall1 ${ }^{1}$, Erman Coşkun ${ }^{2}$ and Mehtap Özşahin ${ }^{3}$ \\ ${ }^{1}$ Sakarya University, Turkey \\ ${ }^{2}$ Prince Mohammad Bin Salman College (MBSC) of Business \& Entrepreneurship, Saudi Arabia \\ ${ }^{3}$ Yalova University, Turkey
}

\begin{abstract}
While ICT adoption and utilization are essential for all kind of companies for various reasons, it could be especially essential for SMEs for their sustainability and innovativeness. ICT awareness and perception is the main determinants of ICT adoption and utilization. In SMEs, ICT adoption and utilization will be dependent on a) owner/manager's individual characteristics, b) owner/manager's ICT awareness c) company related features. Thus, this study aims to investigate: (1) effects of company characteristics, owner/manager's individual characteristics and ICT awareness on ICT adoption and utilization (2) how the extent of ICT adoption and utilization influences different aspects and types of innovativeness. Mixed approach combining quantitative and qualitative research methods is used for gaining insight related to subject and the studied phenomenon. Data gathered from semi-structured interviews, and a developed questionnaire applied to SMEs are synthesized to reveal findings regarding the determinants of ICT adoption and utilization levels of SMEs.

The developed model is being tested in Turkish SMEs. Moreover, the effects of ICT adoption and utilization levels on the components of organizational innovativeness are investigated comprehensively in this study.
\end{abstract}

\section{KEYWORDS}

ICT adoption, ICT awareness, Organizational innovativeness, SMEs

\section{INTRODUCTION}

Small and medium enterprises (SMEs) are drivers of the economy by constituting a major role in creating employment opportunities and developing innovations, because of agile and flexible processes. In OECD countries, SMEs constitute a remarkable part of the total enterprises, and make the greatest contribution to the economy (Scupola, 2009, as cited in Awa, Ojiabo, \& Emecheta, 2015). Concentrating on SMEs, associated literature has highlighted several advantages of adopting ICT from the point of cost savings, enhancement of services, creation of new opportunities, improved access to market information, increased organizational performance and competitiveness (Giotopoulos et al., 2017; Quinton et al., 2018). Consequently, digital technologies have shifted the way in which organizations interact with the environment and their solutions to problems stemming from the business environment. Growing utilization of ICTs is the major driver of the knowledge economy (Kossaï \& Piget, 2014). ICTs compromising a broad range of technological implementations, digital and telecommunication technologies and digital information facilities, are promising for advancement of SMEs (Ismail et al., 2011, as cited in Ibrahim et al., 2016). Although digitalization is not a recent concept, SMEs might not get full benefits from digitalization due to limited financial, technical resources, skilled and knowledgeable workers and adequate experience. They have considerable barriers in front of technology adoption (Dahnil et al., 2014). Nguyen, Newby and Macaulay (2015) mentioned non-existence of proper business and ICT strategies, insufficient research and planning, inadequate project management, and missing top management support as barriers in front of successful ICT adoption. Similarly, Makiwa (2018) put emphasis into insufficient organizational strategies, limited guidance and inadequate policies. 


\section{CONCEPTUAL BACKGROUND}

Theories including "Technology Acceptance Model" (Davis, 1985) and "Diffusion of Innovation" theory (Rogers, 1983) and "Technology-Organization and Environment" (TOE) (Tornatzky \& Fleischer, 1990) framework have been widely adopted to examine adoption process and decision-making in different contexts. Diffusion and Innovations Theory and TOE framework focus on both organizational and individual level characteristics. TOE, furthermore, emphasizes the remarkable role of environment by considering competitors, government and industry in which the firm operates (Giotopoulos et al., 2017). Depending on these theories, this study proposes a conceptual model by incorporating individual and organizational characteristics in terms of ICT awareness of owners/managers, organizational innovativeness and some particular demographic characteristics in order to examine ICT adoption at SMEs. ICT adoption behavior is evaluated by means of a framework that emphasizes ICT infrastructure and ownership, the extent of internal and external integration, utilization of Internet and e-business activities.

\subsection{Determinants of ICT Adoption and Utilization}

Adoption of ICT, its determinants and consequences have been topic of numerous studies. Awa et al. (2015) investigated e-commerce adoption of SMEs and its determinants associated with technology, organization and environment. Kusumaningtyas \& Suwarto (2015) examined ICT adoption with regard to some demographical factors of owners / managers. Age and education level were significantly determined differences in ICT adoption, use and skills, while gender did not demonstrate significant effect. Thong (1999) mentioned CEO characteristics and IS characteristics in addition to organizational and environmental factors (as cited in Taylor, 2015). In this context, the following assumption is developed:

A1: Demographic characteristics of owners/managers of SMEs in terms of age, education level and training field affect the ICT adoption level of SMEs.

Kim, Jang and Yang, (2017) specifically focused on the adoption of Software-as-a-Service (SaaS). Perceived benefits and risks within technological, organizational and environmental contexts were investigated with regard to their influence on intention to adopt SaaS. Ramayah et al., (2016) focused on the level of web adoption and antecedents were determined as follows: innovativeness of CEO, perceived advantages, cost and attitudes towards information technologies. Al Isma'ili, Li, Shen and $\mathrm{He}$ (2016) examined cloud-computing adoption at SMEs. Technological factors compromising "cost reduction, compatibility, relative advantages and trialability", organizational factors including "size, organizational innovativeness, information systems knowledge and top management support" were explored as significant predictors of cloud computing adoption. Giotopoulos et al. (2017) discovered that innovative activities and research \& development, qualified employees, proper guidance and leadership, and decentralization of decision-making enhances adoption of up-to-date technologies in SMEs. Esmaeilpour et al. (2016) focused on e-commerce adoption at SMEs and found that all kind of barriers (organizational, technical and environmental barrier), had significant effect on perceived usefulness and ease of use, which significantly determined intention to use e-commerce. As been indicated in most of earlier researches, the characteristics and perceptions of top management play a great role in ICT adoption of organizations. In this respect, it is proposed that:

A2. ICT awareness of owners/managers of SMEs affects the ICT adoption level of SMEs.

Sin Tan et al. (2010) investigated the demographic characteristics of SMEs as antecedents of ICT adoption. ICT benefits and perceived barriers were focused on so as to determine differences among companies based on industry type, size, size in terms of annual sales and years of internet experience. There were significant differences in terms of perceptions of benefits and barriers based on demographic properties of companies. For instance, relative advantage and perceived benefits were mentioned by (Iacovou et al., 1995; Merthens et al., 2001; Premkumar \& Roberts, 1999, as cited in Taylor, 2015). Relative to large-scale organizations, SMEs view the implementation expensive, risky and complicated procedure, which constitutes an important barrier in front of adoption (Dahnil et al., 2014). Accordingly, researchers propose that:

A3. Organizational features of SMEs in terms of size, lifespan, industry and annual revenue affect the ICT adoption level of SMEs. 


\subsection{ICT Adoption - Organizational Innovativeness}

Martins and Terblanche (2003) conceptualized organizational innovativeness based on: behaviour towards encouragement, strategy, support mechanisms and structure (as cited in Jaakson et al., 2019). Martínez-Román and Romero (2017) examined innovativeness of SMEs from the aspects of product, process, marketing and organization. Based on earlier studies, Wang and Ahmed (2004) conceptualized OI with five dimensions including strategic, product, process, behavioral and market innovativeness. The relationship between innovativeness and ICT adoption examined by numerous studies. For instance, Adeniran and Johnston (2015) examined impact of innovativeness within dynamic capabilities of organizations and their ICT adoption on achieving competitiveness. Similarly, Giotopoulos et al. (2017) investigated the influence of organizational innovations as technological competency on ICT adoption. On the other hand, Neirotti and Pesce (2019) argued that, ICTs offer opportunity of performing various innovation activities as a result of facilitating automation, information processing and providing mechanisms for complex product development. Moreover, Valdez-Juárez et al. (2018) explored that ICT had significant effect on innovation, KM and profitability. Parallel to Neirotti and Pesce (2019) and Valdez-Juárez et al. (2018), our study also emphasizes the effect of ICT adoption level on organizational innovativeness. Wang and Ahmed (2004) conceptualized market and product innovativeness as externally-focused and market-based inter-twins; whereas, behavioral and process innovativeness as internally-focused inter-twins, which emphasizes the need for product and market innovativeness. On the other hand, strategic innovativeness captures the features of both sides as it emphasizes the organization's ability to match external opportunities with internal capabilities in order to introduce innovative products and exploit new markets. In this respect, it is expected that ICT adoption levels influence different types of innovativeness in different ways. Based on these, the following assumptions were developed;

A4: Different levels of ICT adoption affect different components of organizational innovativeness.

$A 4_{a}$ : Basic communication, basic ICT utilization and internal integration levels of ICT adoption affect behavioral and process innovativeness significantly.

$A 4_{b}$ : External integration and inter-organizational integration levels of ICT adoption affect market and product innovativeness significantly.

A4 $4_{c}$ : Strategic integration level of ICT adoption affect strategic innovativeness significantly.

Based on all these assumptions and literature review we constructed our research model in Figure-1.

\section{METHODOLOGY}

Purpose: This study aims (1) to investigate the effect of individual characteristics -in terms of demographic factors and ICT awareness of owners/managers of SMEs-, and organizational factors -in terms of organizational features of SMEs- on ICT adoption level, and (2) to examine how the extent of ICT adoption influences different aspects of innovativeness. Research Method and Sample: This survey is currently being conducted on SMEs, operating in Marmara Region-Turkey. This research follows a mixed methodology by integrating both qualitative and quantitative research methods. In the case of qualitative approach, semi-structured in depth interviews are used to understand and reflect entrepreneurs' views, and to synthesize findings with the quantitative results for gaining deep insight into phenomenon. The researchers, using convenience-sampling technique, targeted entrepreneurs, who are owners or managers in SMEs. On the other hand, in the case of quantitative research method, questionnaire survey is being executed on SMEs. Besides the owner/manager of the SME, two other employees are asked to fill out the questionnaire. Hence, three participants from each SMEs are targeted to fill out questionnaire to achieve more reliable and valid results. Measures: In in-depth interview questions are based on literature findings, and included $\mathrm{f} 8$ open-ended and 5 closed-ended questions. In context of quantitative research, questionnaire form is composed of two parts. First part includes the questions related to demographic characteristics of participants (e.g. age, education level, gender of participant) and enterprises (e.g., establishment year, size, annual revenue, industry). Second part includes the questions about ICT awareness, ICT adoption and innovativeness of SMEs. All scales at second part are adopted from literature (ICT awareness from Sin Tan et al. 2010; ICT adoption from Alma et al, 2018; innovativeness from Wang and Ahmed, 2004), and based on five point Likert Scale. Analysis Plan: As a part of qualitative research analysis, the responses of 50 entrepreneurs to the in-depth interview questions are coded, and analyzed by three researchers based on triangulation strategy. Moreover, data obtained from quantitative survey, will be analyzed through SPSS statistical package program. To test the model, regression analysis will be performed. 


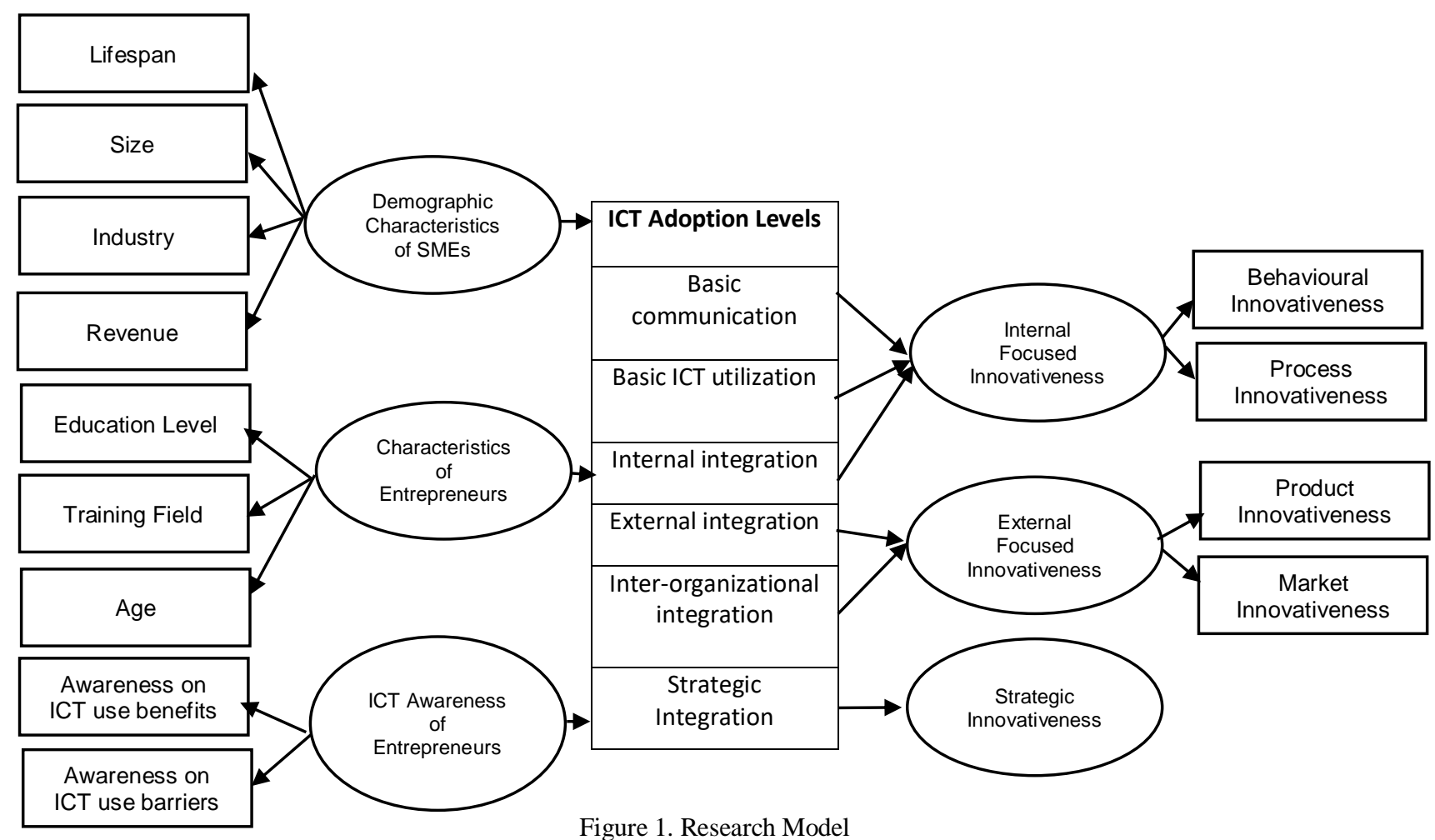

\section{CONCLUSION}

This study, aiming to explore determinants of ICT utilization in SMEs and influence of ICT utilization on innovativeness is expected to provide the following contributions. Firstly, qualitative analysis results are expected to reveal some detailed and context specific findings on the ICT awareness and competency of entrepreneurs, and ICT adoption capability and innovativeness level of their firms. Secondly, quantitative survey conducted to reveal the effects of individual factors, and organizational factors on ICT adoption \& utilization level of SMEs is expected to provide statistical evidence for answering one aspect of the research phenomenon. In this respect, quantitative analyses' results are expected to produce proof of evidence on determinants of ICT adoption levels of SMEs within a developing country context. Thirdly, the effects of ICT adoption and utilization levels on the components of organizational innovativeness are investigated comprehensively through this quantitative research. Although a remarkable number of research have focused on the impact of ICTs on product and process innovation (Neirotti \& Pesce, 2019), to the best of our knowledge, the effects of ICT adoption \& utilization levels in terms of basic communication, basic ICT utilization, internal integration, external integration, inter-organizational integration and strategic integration on the components of organizational innovativeness- behavioral innovativeness, process innovativeness, market innovativeness, product innovativeness and strategic innovativeness are examined comprehensively for the first time in this study, which constitutes the main contribution of the study.

\section{REFERENCES}

Adeniran, T. V., \& Johnston, K. A. (2015). The impacts of ICT utilisation and dynamic capabilities on the competitive advantage of South African SMEs. International Journal of Information Technology and Management, 15(1), 59.

Al Isma'ili, S., Li, M., Shen, J., \& He, Q. (2016). Cloud computing adoption determinants : an analysis of Australian SMEs. Pacific Asia Conference on Information Systems 2016, 1-17. Retrieved from http://ro.uow.edu.au/cgi/viewcontent.cgi?article=6855\&context=eispapers 
Alma, B., Coşkun, E., \& Ozsahin, M. (2018). A Framework Proposal for Examining the Effect of ICT Adoption Level on Innovativeness in SMEs. In Twenty-fourth Americas Conference on Information Systems (pp. 1-10). New Orleans.

Awa, H. O., Ojiabo, O. U., \& Emecheta, B. C. (2015). Integrating TAM, TPB and TOE frameworks and expanding their characteristic constructs for e-commerce adoption by SMEs. Journal of Science \& Technology Policy Management, 6(1), 76-94.

Dahnil, M. I., Marzuki, K. M., Langgat, J., \& Fabeil, N. F. (2014). Factors Influencing SMEs Adoption of Social Media Marketing. Procedia - Social and Behavioral Sciences, 148, 119-126.

Davis, F. D. (1985). a Technology Acceptance Model for Empirically Testing New End-User Information Systems: Theory and Results. MASSACHUSETTS INSTITUTE OF TECHNOLOGY.

Esmaeilpour, M., Hoseini, S. Y., \& Jafarpour, Y. (2016). An empirical analysis of the adoption barriers of e-commerce in small and medium sized enterprises (SMEs) with implementation of technology acceptance model. Journal of Internet Banking and Commerce, 21(2).

Falahat, M., Tehseen, S., \& Van Horne, C. (2018). Entrepreneurial innovativeness and ITS impact on smes' performances. International Journal of Entrepreneurship, 22(3), 1-9.

Giotopoulos, I., Kontolaimou, A., Korra, E., \& Tsakanikas, A. (2017). What drives ICT adoption by SMEs? Evidence from a large-scale survey in Greece. Journal of Business Research, 81(December 2016), 60-69.

Ibrahim, A. M., Salleh, M., Hassan, H., Gambo, D., \& Yusuf, S. (2016). Influence of ICT Adoption on Agro-Enterprises: Conceptual Framework and Structural Model. Jurnal PengaJian Media Malaysia / Malaysian Journal of Media Studies, 18(2), 37-54.

Jaakson, K., Aljaste, H., \& Uusi-Kakkuri, P. (2019). Dimensions of organisational innovativeness and company financial performance in the biotechnology sector. International Journal of Manpower.

Kim, S. H., Jang, S. Y., \& Yang, K. H. (2017). Analysis of the Determinants of Software-as-a-Service Adoption in Small Businesses: Risks, Benefits, and Organizational and Environmental Factors. Journal of Small Business Management, 55(2), 303-325.

Kossaï, M., \& Piget, P. (2014). Adoption of information and communication technology and firm profitability: Empirical evidence from Tunisian SMEs. Journal of High Technology Management Research, 25(1), 9-20.

Kusumaningtyas, N., \& Suwarto, D.H.(2015). ICT Adoption, Skill and Use Differences among Small -Medium Enterprises Managers Based on Demographic Factors. Procedia-Social and Behavioral Sciences, 169(August 2014), 296-302.

Makiwa, P. J. (2018). Developing and validating an ict adoption framework for smes in developing countries: A case of Zimbabwe. University of Pretoria.

Martínez-Román, J. A., \& Romero, I. (2017). Determinants of innovativeness in SMEs: disentangling core innovation and technology adoption capabilities. Review of Managerial Science, 11(3), 543-569.

Neirotti, P., \& Pesce, D. (2019). ICT-based innovation and its competitive outcome: the role of information intensity. European Journal of Innovation Management, 22(2), 383-404.

Nguyen, T. H., Newby, M., \& Macaulay, M. J. (2015). Information technology adoption in small business: Confirmation of a proposed framework. Journal of Small Business Management, 53(1), 207-227.

Quinton, S., Canhoto, A., Molinillo, S., Pera, R., \& Budhathoki, T. (2018). Conceptualising a digital orientation: antecedents of supporting SME performance in the digital economy. Journal of Strategic Marketing, 26(5), 427-439.

Ramayah, T., Ling, N. S., Taghizadeh, S. K., \& Rahman, S. A. (2016). Factors influencing SMEs website continuance intention in Malaysia. Telematics and Informatics, 33(1), 150-164.

Rogers, E. M. (1983). Diffusion of Innovations. New York: Free Press.

Sin Tan, K., Chong, S. C., Lin, B., \& Eze, U. C. (2010). Internet-based ICT adoption among SMEs: Demographic versus benefits, barriers, and adoption intention. Journal of Enterprise Information Management, 23(1), $27-55$.

Taylor, P. (2015). The Importance of Information and Communication Technologies (Icts): an Integration of the Extant Literature on Ict Adoption in Small and Medium Enterprises. International Journal of Economics, Commerce and Management, III(5), 274-295. Retrieved from http://ijecm.co.uk/

Tornatzky, L. G., \& Fleischer, M. (1990). The Processes of Technological Innovation. Lexington: Lexington Books.

Valdez-Juárez, L. E., García-Pérez-de-Lema, D., \& Maldonado-Guzmán, G. (2018). ICT and KM, Drivers of Innovation and Profitability in SMEs. Journal of Information \& Knowledge Management, 17(01), 1850007.

Wang, C. L., \& Ahmed, P. K. (2004). The development and validation of the organisational innovativeness construct using confirmatory factor analysis. European Journal of Innovation Management, 7(4), 303-313. 